\title{
Impactos Econômicos do Código Florestal Brasileiro: uma discussão à luz de um modelo computável de equilíbrio geral
}

\author{
Tiago Diniz ${ }^{1}$ e Joaquim Bento Ferreira Filho ${ }^{2}$
}

Resumo: O trabalho analisa os impactos econômicos decorrentes da aplicação do Código Florestal, na sua nova versão e na anterior, sobre o Brasil e suas regiões. Para tanto, foram analisados três cenários distintos de aplicação do código por meio de um modelo de equilíbrio geral inter-regional, o TERM-BR, a partir do qual se podem obter os resultados a nível nacional e regional. Os dados básicos foram obtidos por meio de estudos realizados via imagens de satélite e compatibilizados com as informações de uso do solo provenientes do Censo Agropecuário de 2006. As conclusões mostraram que as restrições mais brandas da nova legislação, de fato, desdobram-se em menores impactos econômicos. Com o novo Código Florestal, a adequação às restrições legais implicaria redução de $0,19 \%$ do PIB do País ou de $0,17 \%$, quando utilizado o mecanismo de compensar o déficit de Reserva Legal em outro estado. Na versão anterior do código, por sua vez, esse percentual seria de 0,37\% do PIB. Esses resultados agregados, contudo, têm diferenças significativas quando analisados entre as regiões do Brasil, uma vez que, regionalmente, as incidências legais são distintas em cada um dos cenários.

Palavras-chaves: Modelos CGE; TERM-BR; Código Florestal do Brasil; Impactos econômicos.

Abstract: This paper analyzes the economic impacts of Brazilian Forest Code, in its different versions, on Brazil and its states. Three different scenarios were analyzed using an interregional computable general equilibrium model, the TERM-BR, from which we obtain national and regional results. Satellite imagery data was combined with economic information from the Brazilian Agricultural Census for the analysis. Model results show that the less restrictive new version of the law resulted in smaller negative economic impacts on the Brazilian economy. With the new law, the Brazilian GDP was reduced by $0.19 \%$, or by $0.17 \%$, when the system for Legal Reserves compensation in other state is used. This is smaller than the projected impact of the previous law, which we estimated to

1. Companhia Hidro Elétrica do São Francisco (CHESF) e Escola Superior de Agricultura "Luiz de Queiroz" - Universidade de São Paulo. Piracicaba, SP, Brasil. E-mail: tiagotbd@gmail.com

2. Escola Superior de Agricultura "Luiz de Queiroz" - Universidade de São Paulo. Piracicaba, SP, Brasil. E-mail: jbsferre@usp.br 
be a $0.37 \%$ reduction in the GDP. However, the results are heterogeneous across regions since the incidence of the restrictions is different in the alternative scenarios.

Key-words: Brazilian Forest Code, economic impacts, Computable General Equilibrium models.

http://dx.doi.org/10.1590/1234-56781806-9479005302003

\section{Introdução}

A legislação ambiental brasileira tem estado na pauta de discussões políticas e econômicas nos últimos anos. A Lei n. 12.651/12 alterou o antigo Código Florestal (Lei n. 4.771/65) após discussões e modificações do seu texto original no Congresso Nacional. Dentre as principais mudanças, estão a criação do Programa de Regularização Ambiental, com o objetivo de desburocratizar a legalização dos produtores em desacordo com a lei, e novos critérios para o cômputo das Áreas de Preservação Permanente (APPs) e das de Reserva Legal (RL). Em relação a esses últimos, a discussão alcançou notoriedade devido às áreas de APP e RL se constituírem, por um lado, importantes mecanismos de preservação ambiental, mas, ao mesmo tempo, limitarem a expansão da atividade agropecuária com prejuízos aos produtores que, estando eventualmente fora das exigências legais, seriam obrigados a reduzir a área cultivada para atendê-las.

Com efeito, Bacha (2005) apresenta dados que mostram que no ano de 1998 apenas 7,04\% dos imóveis rurais do país registravam a presença de RL. Essa área correspondia a somente 9,58\% da área total dos imóveis rurais do Brasil. $\mathrm{Ou}$ seja, para efeito de regularização ambiental, seria necessária a reversão de áreas plantadas, sejam agrícolas ou de pastagens, em vegetação nativa. Nesse sentido, Padilha Júnior (2004) salienta que 3,2 milhões de hectares teriam que ser imobilizados permanentemente para atender a exigência de RL no estado do Paraná. Com base em um
Valor Bruto da Produção (VBP) de R \$ 1.293,96 por hectare, o impacto total dessa exigência poderia, segundo o autor, atingir os $\mathrm{R} \$ 90$ bilhões no estado. De maneira similar, Rigonatto (2009) estimou que o atendimento às exigências de RL no estado de Goiás implicaria perda imediata de $\mathrm{R} \$$ 2,05 bilhões aos produtores.

Nesse contexto, a Lei n. 12.651/2012 inseriu inovações que permitem o aumento da área disponível para as atividades econômicas, ou, sob outra ótica, diminuem as exigências territoriais para regularização ambiental. Dentre os critérios que afetam diretamente as atividades produtivas, as principais diferenças entre a nova legislação e a anterior estão relacionadas concisamente no Quadro 1.

As diferentes exigências em termos de uso do solo das diferentes versões do Código Florestal Brasileiro foram analisadas por Sparovek et al. (2011), por meio de análises de imagens obtidas por sensoriamento remoto. O projeto AgLue faz um mapeamento georreferenciado do território brasileiro a partir de uma ampla base de dados e cruzamento de informações. Dentre as variáveis que podem ser obtidas estão os déficits de APP e de RL na agricultura e na pecuária para as microrregiões do País.

Mesmo com as alterações na legislação, as estimativas apresentadas em Sparovek et al. (2011) evidenciam que apesar de menor do que no antigo Código Florestal, a necessidade de reversão de áreas produtivas em vegetação nativa ainda existe. De acordo com o autor, nas condições do antigo Código Florestal o déficit de APP no País era de 43 
Quadro 1. Comparativo de tópicos selecionados: Código Florestal antigo x Novo Código Florestal

\begin{tabular}{|c|c|}
\hline $\begin{array}{l}\text { Código Florestal antigo } \\
\text { (Lei n. } 4.771 \text { de 1965) }\end{array}$ & $\begin{array}{l}\text { Novo Código Florestal } \\
\text { (Lei n. } 12.651 \text { de 2012) }\end{array}$ \\
\hline $\begin{array}{l}\text { No cálculo das áreas a serem mantidas como Reserva Legal, } \\
\text { eram excluídas as destinadas às APPs. A sobreposição é permi- } \\
\text { tida somente em casos particulares, regidos pelo parágrafo } 6^{0} \\
\text { do art.16. }\end{array}$ & $\begin{array}{l}\text { Admite-se que as Áreas de Preservação Permanente sejam aba- } \\
\text { tidas no cálculo do percentual da Reserva Legal do imóvel, des- } \\
\text { de que isso não implique conversão de novas áreas para o uso } \\
\text { alternativo do solo. }\end{array}$ \\
\hline $\begin{array}{l}\text { O referencial para cômputo das APPs ripárias era o nível mais } \\
\text { alto dos cursos d'agua. }\end{array}$ & O referencial passa a ser a borda da calha do leito regular. \\
\hline $\begin{array}{l}\text { Estabelece delimitações rígidas para as Áreas de Preservação } \\
\text { Permanente e não permite flexibilização no caso de regulari- } \\
\text { zação. }\end{array}$ & $\begin{array}{l}\text { Mantém parte das delimitações da legislação anterior, mas, } \\
\text { para efeito de regularização ambiental, as APPs nas margens } \\
\text { dos cursos d'agua e no entorno de nascentes, olhos d'água, la- } \\
\text { gos e lagoas naturais são reduzidas de acordo com o tamanho } \\
\text { da propriedade. }\end{array}$ \\
\hline $\begin{array}{l}\text { Não há imóveis rurais dispensados de cumprir as exigências da } \\
\text { Reserva Legal }\end{array}$ & $\begin{array}{l}\text { Para os imóveis rurais com até quatro módulos fiscais, a Reser- } \\
\text { va Legal será constituída com a vegetação natural existente até } \\
22 \text { de julho de 2008, mesmo que esta área corresponda a um } \\
\text { percentual inferior àquele determinado em Lei. Para proprie- } \\
\text { dades maiores, são excluídos os quatro módulos fiscais da base } \\
\text { de cálculo da RL. }\end{array}$ \\
\hline $\begin{array}{l}\text { Para fins de recomposição, permite compensar a reserva legal } \\
\text { por outra área equivalente em importância ecológica e exten- } \\
\text { são, desde que pertença ao mesmo ecossistema e esteja locali- } \\
\text { zada na mesma microbacia. }\end{array}$ & $\begin{array}{l}\text { Permite compensar a Reserva Legal inclusive em outras UFs, } \\
\text { desde que a área seja equivalente em extensão à área da Reser- } \\
\text { va Legal a ser compensada e esteja localizada no mesmo bioma. }\end{array}$ \\
\hline
\end{tabular}

Fonte: Lei n. 4.771/1965. Lei n. 12.651/2012. Elaboração dos autores.

milhões de hectares (Mha) e o de RL de 42 Mha, já descontadas destes montantes as áreas de vegetação natural existente. Em um cenário de isenção de quatro módulos fiscais da base de cálculo da RL, critério adotado na nova legislação, o déficit de RL seria de 15 Mha. Logo, a efetiva aplicação do Código Florestal Brasileiro atingiria de forma direta as atividades produtivas associadas à utilização de terras, como a agricultura e a pecuária.

Dessa forma, o objetivo deste trabalho é analisar os impactos que o atendimento às exigências do Código Florestal na sua atual versão e na anterior trariam à economia do País e de suas regiões, em três cenários distintos: um para o antigo e dois para o novo Código Florestal, sendo que para este caso um dos cenários prevê a compensação da RL em outros estados do país. Diferentemente das pesquisas existentes na literatura, a exemplo de Padilha Júnior (2004), Rigonatto (2009) e IPEA (2011), este estudo contempla tanto os efeitos da APP quanto da RL, com seus desdobramentos regionais. Para tanto, são utilizados os dados desagregados do projeto $A g L u e^{3}$, nos quais podem ser observados os déficits ambientais para cada microrregião, e

3. Ver Sparovek et al. (2010) para mais detalhes. um modelo inter-regional de equilíbrio geral, o TERM-BR, a partir do qual se pode, por meio de simulações, mensurar os efeitos impostos pela restrições legais sobre variáveis econômicas.

\section{Metodologia}

Os modelos computáveis de equilíbrio geral (CGE), de forma geral, são representações do conjunto da economia em seu âmbito global, nacional e/ou regional e são estruturados com base em blocos de equações que especificam o comportamento e as relações entre os agentes econômicos, tais como as famílias, o governo e o setor de produção. Assim, dentre outras características, os modelos CGE permitem que sejam observados através de simulações os impactos de uma política em toda a economia.

O modelo utilizado neste trabalho, o TERM$\mathrm{BR}^{4}$, é estático e inter-regional com estrutura

4. O modelo TERM, desenvolvido originalmente para a Austrália, também tem sido utilizado e adaptado para a avaliação de políticas em outros países, como a Finlândia, a China, a Indonésia e o Japão. Para uma descrição detalhada da estrutura do TERM e de seus fluxos e equações, ver Horridge (2011), Fachinello (2008) e Moraes (2010). 
Figura 1. Estrutura de produção do modelo TERM-BR

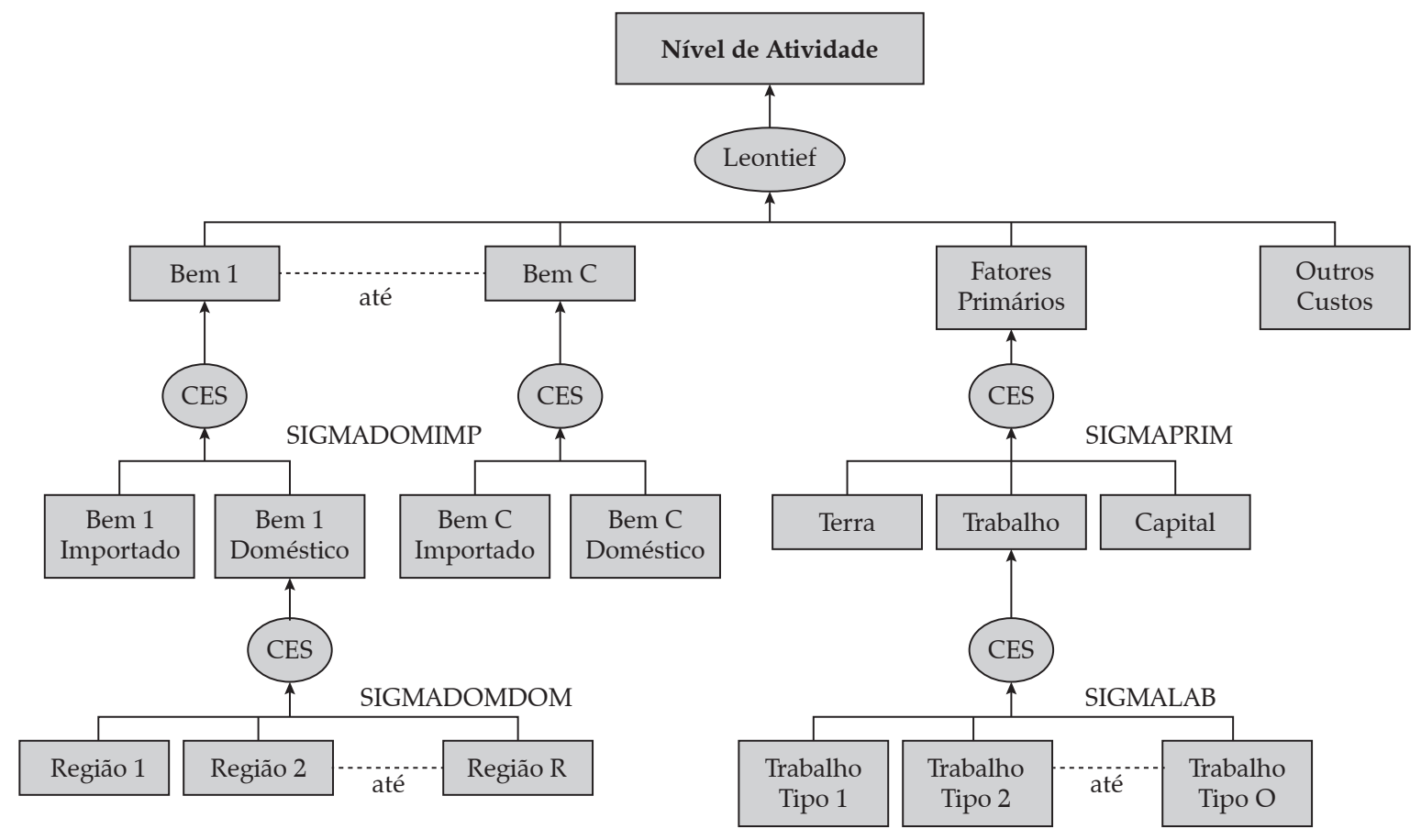

Fonte: Adaptado de Fachinello (2008).

bottom-up, baseado em versões anteriores desenvolvidas Ferreira Filho e Horridge (2006a e 2006b), o que permite a modelagem dos choques de política ao nível estadual, bem como que posteriormente os resultados sejam também obtidos para o País. Basicamente, o TERM-BR consiste de 27 modelos interdependentes, um para cada unidade da federação (UF), interligados por matrizes de comércio nos mercados de produtos e fatores. Dessa forma, o modelo permite que a estrutura produtiva - produção dos setores econômicos, pagamentos aos fatores, impostos e margens, consumo das famílias, etc - de cada UF seja representada separadamente, ao passo que as suas interligações se dão por meio de fluxos comerciais e pelo mercado de trabalho, uma vez que o fator trabalho é móvel entre as atividades e regiões/ estados. A Figura 1 ilustra o sistema de produção do TERM-BR, apresentando os mecanismos de decisão dos agentes na produção, as formas funcionais e a relação entre as regiões para a composição dos bens domésticos.
O modelo é calibrado para o ano de 2005, utilizando-se a Matriz de Insumo-Produto de 2005 e outras bases de dados oficiais que caracterizam a economia, como a Pesquisa Nacional por Amostra Domiciliar (PNAD), a Pesquisa de Orçamento Familiar (POF) e a Pesquisa Agrícola Municipal (PAM). Para a finalidade deste trabalho, o modelo foi agregado em vinte e um setores (indústrias) dos quais 15 são da agropecuária, sendo 12 da agricultura, dois da pecuária e um representando as demais atividades agropecuárias. As elasticidades utilizadas nas equações comportamentais do modelo foram obtidas na literatura especializada, em trabalhos como o de Tourinho (2003) e GTAP (2008) $)^{5}$. O Quadro 2 apresenta os setores considerados para a agregação da base de dados ${ }^{6}$.

5. Os valores específicos são omitidos aqui por uma questão de espaço. Podem, contudo, ser obtidas com os autores sob solicitação.

6. A agregação prioriza os setores ligados à agropecuária, devido ao escopo deste estudo. 
Quadro 2. Setores econômicos do modelo TERM-BR

\begin{tabular}{|l|l|l|l|}
\hline \multicolumn{2}{|c|}{ Agropecuária } & \multicolumn{1}{c|}{ Indústria } & \multicolumn{1}{c|}{ Serviços } \\
\hline 1. Arroz em Casca & 9. Algodão Herbáceo & Extrativa Mineral & Comércio \\
\hline 2. Milho em Grão & 10. Frutas Cítricas & Agroindústria & Transporte \\
\hline 3. Trigo e Outros Cereais & 11. Café em Grãos & Indústria & Serviços \\
\hline 4. Cana de Açúcar & 12. Exploração Florestal e Silv. & & \\
\hline 5. Soja em Grão & 13. Bovinos e Outros Animais & & \\
\hline 6. Outros Prod e Serv. Lavouras & 14. Leite Vaca e Outros Animais & & \\
\hline 7. Mandioca & 15. Outros Prod da Pec. e Aquicultura & & \\
\hline 8. Fumo em Folha & & & \\
\hline
\end{tabular}

Fonte: Dados da pesquisa.

\subsection{Estratégia de simulação}

Conforme já assinalado, a legislação ambiental condiciona a atividade econômica por meio de limitações impostas ao uso do solo, sobretudo através dos instrumentos da Área de Preservação Permanente (APP) e da Reserva Legal (RL). Dessa forma, a ligação entre as determinações do Código Florestal e o modelo econômico é feita por meio de restrições a utilização do fator primário terra por parte dos setores produtivos, mais especificamente pelos segmentos da agropecuária, que são diretamente afetados pelas restrições legais.

Levando em conta as observações de Bacha (2005) e Sparovek et al. (2011), a maior parte dos imóveis rurais e praticamente todas as regiões do País registram passivos ambientais. Desta forma as simulações consistem, basicamente, de um choque negativo (redução) no uso do fator terra, por setor de atividade e por UF, enquanto a produção, que é endógena ao modelo, ajusta-se para esta nova condição. A partir da Figura 1 é possível observar os encadeamentos no sistema produtivo de um choque sobre o fator de produção terra.

Deve-se ressaltar que os impactos sobre o nível de atividade de uma determinada indústria/setor não são proporcionais à redução que esta sofrerá no uso da terra, dada a substituição que pode ocorrer entre a utilização dos fatores primários (capital, trabalho e terra), guiada no modelo pelos preços relativos dos fatores. Dessa forma, espera-se que os impactos na produção agropecuária, e consequentemente na economia, sejam inferiores a redução percentual no uso do fator terra que foi simulada.
A base de dados do TERM-BR e dos modelos CGE, de forma geral, retratam apenas os aspectos econômicos da estrutura produtiva. Os valores que compõem o pagamento ao fator primário terra, por exemplo, dizem respeito ao uso desse fator para a produção agropecuária. Assim, a economia não é afetada no modelo no caso de parte compensação de APP ou RL ser feita em vegetação nativa, pois nenhum dos setores produtivos do modelo estaria utilizando essa área para a produção. A esse respeito, destaca-se que os choques utilizados nesta pesquisa já descontam a vegetação natural existente e, portanto, representam os déficits que realmente devem ser compensados pelos setores produtivos e que, por conseguinte, afetam o sistema econômico.

Isso posto, imprimiu-se ao modelo um fechamento (comportamento) de longo prazo em que a produção se ajusta endogenamente às novas condições de utilização do fator de produção terra. Assim, foram assumidas as seguintes premissas:

a) Pleno emprego. A mão-de-obra pode deslocar-se entre as regiões e entre os setores de acordo com o salário relativo. Admite-se, contudo, que esta política não afeta a taxa natural de desemprego da economia, o que é equivalente a dizer que o emprego agregado não varia nas simulações.

b) Acumulação do capital endógena, sendo o seu aumento associado à taxa de lucro setorial. A taxa de retorno ao capital é fixa para todos os setores ao nível do ano base.

c) O consumo das famílias é endógeno e os gastos do governo seguem a mesma tendência do consumo familiar. 
d) A demanda por investimentos é endógena e determinada pela rentabilidade dos setores.

e) A demanda do resto do mundo pelas exportações de cada UF brasileira é determinada por uma curva de demanda por exportações, negativamente inclinada. Dessa forma, as exportações domésticas aumentam caso o preço relativo dos produtos domésticos se reduza em relação ao preço externo exógeno.

f) Taxa de câmbio nominal endógena ao modelo.

g) $\mathrm{O}$ índice de preços ao consumidor é o "numéraire" do modelo.

\section{Compatibilização dos dados}

Parte importante deste trabalho é o cálculo dos choques de política, que são os percentuais que os setores agropecuários terão que reduzir na utilização do fator de produção terra para se adequarem às exigências legais. Para isso, é necessária a conversão das informações físico-geográficas do projeto $A g L u e$, do qual são obtidos os déficits de APP e RL para cada microrregião do país em milhões de hectares (Mha), em dados econômicos que possam ser inseridos no TERM-BR. Na realização da compatibilização utilizou-se o Censo Agropecuário de 2006 de acordo com a metodologia descrita a seguir.

\subsection{Compatibilização de dados entre o AgLue e o Censo Agropecuário}

No âmbito do projeto AgLue, Sparovek et al. (2010) calcularam, através do cruzamento de uma base de informações geográficas obtidas por sensoriamento remoto e de um algoritmo computacional que leva em conta a legislação ambiental, o déficit de APP e RL na agricultura e na pecuária para o Brasil, inclusive com desagregações por biomas, UFs e microrregiões. Esse cômputo pôde ainda ser simulado para as várias propostas de alteração do Código Florestal, conforme apresentado em Sparovek et al. (2011).
De posse dessa base de dados, é possível computar a proporção entre o déficit de APP e RL na agricultura e a área agrícola, assim como o seu correspondente para a pecuária, por microrregião geográfica. Isso feito, esse indicador de déficit é aplicado como fator de redução da área colhida (área de pastagem, no caso da pecuária) das atividades agropecuárias em cada microrregião, utilizando as informações do Censo Agropecuário do ano de 2006. Sobre esse processo, vale destacar alguns pontos:

a) No cálculo do déficit de APP e RL realizado no AgLue já é descontada a vegetação natural existente, conforme mencionado anteriormente, de forma que o indicador de déficit utilizado só reduz a área colhida das culturas agrícolas (ou pecuárias) quando estas realmente precisarem ser suprimidas para a adequação ambiental;

b) No caso da Reserva Legal, assume-se que uma microrregião irá, após já descontada sua vegetação natural, primeiramente utilizar a área ocupada pela pecuária para compensar a RL. Caso esta não seja suficiente, as áreas ocupadas pelas culturas agrícolas são utilizadas para tal finalidade. Esse procedimento é adotado pelo fato da pecuária, em geral, ter produtividade da terra relativamente baixa quando comparada com a agricultura ${ }^{7}$.

c) O indicador de déficit é aplicado uniformemente entre as culturas existentes em cada microrregião. Deve-se ressaltar que esse procedimento preserva muito das especificidades regionais em termos da composição da produção, uma vez que a esse nível de unidade territorial, na ampla maioria dos casos, o plantio é concentrado em até três culturas.

7. As séries históricas de preços do arrendamento da terra da Fundação Getúlio Vargas (FGV) mostram pagamentos menores para as áreas destinadas a atividade pecuária, evidenciando, assim, sua menor produtividade relativa. 
Os dados obtidos (a área colhida, ou de pastagem, a ser reduzida em cada atividade agropecuária, por microrregião) são agregados de duas formas. Primeiro, as culturas do Censo Agropecuário são reclassificadas para os 15 setores agropecuários do modelo TERM-BR e, a seguir, as informações microrregionais são agregadas para o nível estadual. O resultado desse processo é a obtenção, por UF, dos percentuais pelos quais cada uma das 15 atividades agropecuárias precisaria ter reduzida sua área colhida ou de pastagens para se adequar à legislação. Os percentuais são obtidos de forma separada, sendo possível verificar a incidência da APP e da RL isoladamente e para cada uma das versões do Código Florestal.

\section{Cenários para simulação}

Foram realizadas simulações para três cenários, sendo um para o antigo Código Florestal e dois para a sua nova versão. Das limitações impostas pelos mecanismos da APP e RL destacam-se para efeito de simulação as restrições sumarizadas no Quadro 3, no qual é também possível verificar as diferenças entre os cenários.
O primeiro cenário, que trata da versão anterior do Código Florestal, é o mais restritivo, no qual não existem isenções para os produtores rurais que estão irregulares com a legislação ambiental. De acordo com os dados do AgLue, para esse cenário o déficit de APP é de 55 Mha e o de RL é de 49Mha, ambos para o Brasil. Após efetuada a compatibilização entre esses dados e os do Censo Agropecuário, os resultados obtidos mostram a necessidade de reversão de cerca de 39,3 Mha de área colhida (ou de pastagem) para atender as exigências de APP e de 35,4 Mha para a Reserva Legal.

Em termos estaduais, os percentuais de redução são bastante heterogêneos, como pode ser observado na Tabela 1. Estados cujos territórios situam-se no bioma Amazônia, portanto com uma elevada exigência de RL, tendem a ter que reverter uma proporção maior de suas áreas produtivas do que os demais, a exemplo do Amazonas e do Amapá. Por outro lado, a reversão de áreas para o atendimento à APP é relativamente maior em UFs que têm predomínio de culturas de várzeas e/ou aquelas típicas de terrenos acidentados, como é o caso do Espírito Santo e do Rio de Janeiro.

Quadro 3. Descrição dos cenários propostos para a simulação do Código Florestal

\begin{tabular}{|c|c|c|}
\hline $\begin{array}{l}\text { Código Florestal antigo } \\
\text { (Lei n. } 4.771 \text { de 1965) }\end{array}$ & \multicolumn{2}{|c|}{$\begin{array}{l}\text { Novo Código Florestal } \\
\text { (Lei n. 12.651 de 2012) }\end{array}$} \\
\hline Cenário 1 & Cenário 2 & Cenário 3 \\
\hline $\begin{array}{l}\text { - Compensação do déficit de APP em sua } \\
\text { totalidade; } \\
\text { - Não há descontos no cômputo da Re- } \\
\text { serva Legal; } \\
\text { - RL de } 80 \% \text { para a Amazônia Legal; } \\
\text { - RL compensada dentro do mesmo imó- } \\
\text { vel rural. }\end{array}$ & $\begin{array}{l}\text { - Compensação de } 50 \% \text { do déficit de APP } \\
\text { ripária e total do déficit de APP de topo } \\
\text { de morro; } \\
\text { - São descontados no cômputo da Reser- } \\
\text { va Legal: } 4 \text { módulos fiscais e a Vegeta- } \\
\text { ção Natural existente nas APPs; } \\
\text { - RL de } 50 \% \text { para a Amazônia Legal; } \\
\text { - RL compensada dentro do mesmo imó- } \\
\text { vel rural. }\end{array}$ & $\begin{array}{l}\text { - Compensação de } 50 \% \text { do déficit de APP } \\
\text { ripária e total do déficit de APP de topo } \\
\text { de morro; } \\
\text { - São descontados no cômputo da Reser- } \\
\text { va Legal: } 4 \text { módulos fiscais e a Vegeta- } \\
\text { ção Natural existente nas APPs; } \\
\text { - RL de } 50 \% \text { para a Amazônia Legal; } \\
\text { - RL compensada fora do imóvel rural } \\
\text { (em outra UF), mas no mesmo bioma. }\end{array}$ \\
\hline
\end{tabular}

Fonte: Lei n. 4.771/65. Lei n. 12.651/12. Elaboração dos autores. 
Tabela 1. Cenário 1 e 2: \% de redução da área colhida (ou de pastagem) para adequação ao Código Florestal antigo e ao Novo Código Florestal, por UF

\begin{tabular}{|c|c|c|c|c|c|c|}
\hline \multirow{2}{*}{ UF } & \multicolumn{3}{|c|}{ Cenário 1 (CF antigo) } & \multicolumn{3}{|c|}{ Cenário 2 (Novo CF) } \\
\hline & $A P P(\%)$ & $R L(\%)$ & Total (\%) & $A P P(\%)$ & $R L(\%)$ & Total (\%) \\
\hline Rondônia & 8,72 & 37,46 & 46,18 & 5,17 & 30,22 & 35,39 \\
\hline Acre & 10,69 & 43,79 & 54,48 & 5,35 & 22,11 & 27,46 \\
\hline Amazonas & 24,93 & 70,88 & 95,81 & 13,44 & 6,09 & 19,53 \\
\hline Roraima & 10,34 & 19,17 & 29,51 & 5,64 & 1,70 & 7,34 \\
\hline Pará & 17,77 & 37,61 & 55,37 & 9,99 & 27,05 & 37,04 \\
\hline Amapá & 29,90 & 57,21 & 87,11 & 15,46 & 4,33 & 19,80 \\
\hline Tocantins & 13,61 & 16,39 & 30,00 & 7,63 & 13,47 & 21,10 \\
\hline Maranhão & 21,34 & 28,27 & 49,60 & 13,92 & 19,35 & 33,27 \\
\hline Piauí & 15,58 & 2,25 & 17,83 & 9,29 & 0,93 & 10,22 \\
\hline Ceará & 17,94 & 3,88 & 21,82 & 9,65 & 1,31 & 10,97 \\
\hline Rio Grande do Norte & 33,07 & 4,88 & 37,94 & 17,62 & 2,97 & 20,58 \\
\hline Paraíba & 22,34 & 4,39 & 26,73 & 12,25 & 2,14 & 14,38 \\
\hline Pernambuco & 28,84 & 5,84 & 34,69 & 19,04 & 2,95 & 21,98 \\
\hline Alagoas & 27,96 & 7,96 & 35,92 & 17,89 & 4,05 & 21,94 \\
\hline Sergipe & 23,79 & 12,17 & 35,96 & 12,40 & 4,56 & 16,95 \\
\hline Bahia & 24,11 & 10,19 & 34,30 & 14,19 & 6,54 & 20,73 \\
\hline Minas Gerais & 25,49 & 9,87 & 35,35 & 17,14 & 6,04 & 23,18 \\
\hline Espírito Santo & 43,28 & 33,02 & 76,30 & 28,76 & 32,87 & 61,63 \\
\hline Rio de Janeiro & 40,80 & 16,24 & 57,04 & 25,83 & 11,93 & 37,76 \\
\hline São Paulo & 13,71 & 22,68 & 36,39 & 8,46 & 21,31 & 29,77 \\
\hline Paraná & 19,24 & 10,55 & 29,80 & 14,82 & 8,96 & 23,77 \\
\hline Santa Catarina & 29,39 & 6,72 & 36,11 & 20,42 & 5,29 & 25,71 \\
\hline Rio Grande do Sul & 26,43 & 12,76 & 39,18 & 16,23 & 10,41 & 26,64 \\
\hline Mato Grosso do Sul & 10,03 & 5,31 & 15,34 & 5,62 & 4,22 & 9,84 \\
\hline Mato Grosso & 10,57 & 32,88 & 43,45 & 6,22 & 20,36 & 26,58 \\
\hline Goiás & 14,33 & 6,60 & 20,93 & 8,75 & 4,59 & 13,34 \\
\hline Distrito Federal & 18,18 & 8,60 & 26,78 & 15,35 & 7,20 & 22,55 \\
\hline
\end{tabular}

Fonte: Dados da pesquisa. Elaboração dos autores.

Quando analisados os percentuais de redução nas atividades agropecuárias, é possível verificar na Tabela 2 que quase todo o atendimento às exigências de RL é feito por meio de áreas de pastagens. Com efeito, esse resultado era esperado visto que dos 275 Mha dedicados à agropecuária no Brasil, 211 Mha são de pastos (SPAROVEK et al., 2011). Ademais, como já destacado, o algoritmo de cálculo da compensação da Reserva Legal ao nível microrregional utiliza as áreas de pastagem como as primeiras a serem revertidas em vegetação nativa, sendo as terras agrícolas somente utilizadas na insuficiência daquelas. Por conseguinte, nas atividades agrícolas a maior necessidade de reversão é para o atendimento à $\mathrm{APP}$, fazendo com que culturas com presença extensiva em terrenos acidentados, várzeas e topos de morros, sejam as mais afetadas, a exemplo do café e do arroz.

O segundo cenário, por sua vez, simula o Novo Código Florestal, cujas limitações são mais brandas e permitem a isenção de quatro módulos fiscais, bem como da vegetação nativa das Áreas de Preservação Permanente, da base de cálculo da Reserva Legal. Além disso, as exigências para compensação da APP ripária são menores e na Amazônia Legal o percentual da propriedade dedicado à área de RL passa a ser de $50 \%$. Com essas considerações, os dados do AgLue mostram um déficit de APP em 33,2 Mha e o de RL em 30,7 Mha. Já nas informações compatibilizadas esses valores são de 24,4 Mha e de 24,6 Mha, respec- 
Tabela 2. Cenário 1 e 2: \% de redução da área colhida (ou de pastagem) para adequação ao Código Florestal antigo e ao Novo Código Florestal no Brasil, por setores agropecuários

\begin{tabular}{l|ccc|ccc}
\hline \multirow{2}{*}{ Setor Agropecuário } & \multicolumn{3}{|c|}{ Cenário 1 (CF antigo) } & \multicolumn{3}{c}{ Cenário 2 (Novo CF) } \\
\cline { 2 - 7 } & APP (\%) & $R L(\%)$ & Total (\%) & APP (\%) & RL (\%) & Total (\%) \\
\hline 1. ArrozCasca & 22,80 & 0,65 & 23,45 & 15,33 & 0,33 & 15,66 \\
2. MilhoGrao & 13,88 & 0,91 & 14,79 & 10,04 & 0,61 & 10,65 \\
3. TrigoOutCere & 22,61 & 2,64 & 25,25 & 15,56 & 2,21 & 17,78 \\
4. CanaDeAcucar & 19,04 & 3,42 & 22,45 & 13,00 & 2,34 & 15,34 \\
5. SojaGrao & 14,90 & 1,46 & 16,37 & 10,41 & 1,18 & 11,59 \\
6. OutPrServLav & 13,72 & 0,70 & 14,42 & 9,99 & 0,18 & 10,17 \\
7. Mandioca & 24,17 & 4,03 & 28,20 & 16,79 & 0,17 & 16,96 \\
8. FumoFolha & 28,23 & 0,87 & 29,10 & 20,01 & 0,71 & 20,72 \\
9. AlgodHerb & 7,84 & 3,55 & 11,38 & 5,55 & 2,50 & 8,05 \\
10. FrutasCitric & 12,57 & 4,62 & 17,19 & 8,15 & 3,58 & 11,73 \\
11. CafeGrao & 25,59 & 1,80 & 27,39 & 19,92 & 0,69 & 20,61 \\
12. ExplFlorSilv & 22,38 & 0,33 & 22,71 & 16,13 & 0,17 & 16,30 \\
13. BovOutrAnim & 17,77 & 22,30 & 40,07 & 10,46 & 15,44 & 25,90 \\
14. LeitVacOuAni & 24,70 & 19,12 & 43,82 & 15,13 & 14,05 & 29,18 \\
15. OutPecAcq &.. &.. &.. &.. & &.. \\
\hline
\end{tabular}

Fonte: Dados da pesquisa. Elaboração dos autores.

tivamente para a APP e a RL. Ou seja, totalizam 25,7 milhões de hectares a menos que as exigências do Cenário 1.

Geograficamente, os percentuais de redução da área colhida em decorrência do instrumento da APP diminuíram substancialmente neste cenário em relação ao anterior, até mesmo naqueles estados em que os terrenos são predominantemente acidentados e com elevada incidência da APP de topo de morro (ver Tabela 1). No que tange à RL, observa-se uma redução ainda mais notável quando comparada com os resultados do Cenário 1, sobretudo nos estados com territórios situados na Amazônia Legal, a exemplo do Amazonas. Os menores percentuais são, naturalmente, reflexos diretos das exigências menos severas deste cenário, como o abatimento da vegetação natural existente em APPs e dos quatro módulos fiscais da base de cálculo da RL.

Setorialmente, cabe observar que as culturas agrícolas praticamente não são afetadas pelo instrumento da RL, como pode ser visto na Tabela 2 , enquanto que os percentuais incidentes sobre os segmentos da pecuária são elevados, embora tenham se reduzido neste cenário por causa das hipóteses assumidas. Em relação à APP, os cho- ques mais elevados ainda são aqueles referentes às culturas predominantes em áreas de várzea e de topo de morro, como o Café. Outras atividades, a exemplo do Algodão e das Frutas Cítricas, são pouco afetadas por este instrumento.

Os percentuais de redução da área colhida (ou de pastagem) calculados no Cenário 3, por sua vez, serão apresentados na sexta seção deste trabalho, uma vez que a modelagem de compensação de RL em outra UF é mais complexa e utiliza-se de alguns resultados econômicos que serão gerados nas simulações dos cenários 1 e 2 .

\section{Impactos econômicos: cenário 1 e cenário 2}

Os impactos econômicos das restrições impostas pela legislação ambiental são, tanto em termos nacionais como territoriais, relativamente maiores no Cenário 1. De acordo com os dados da Tabela 3, o efetivo cumprimento do antigo Código Florestal implicaria uma redução de $0,37 \%$ do Produto Interno Bruto (PIB) do país, ao passo que para o novo CF esta retração seria de $0,19 \%$. Ao se analisar de forma isolada os instrumentos da APP 
Tabela 3. Impactos econômicos (variação \%) do antigo e do novo Código Florestal sobre variáveis selecionadas, Brasil

\begin{tabular}{l|ccc|ccc}
\hline \multirow{2}{*}{\multicolumn{1}{c|}{ Variáveis }} & \multicolumn{3}{c|}{ Cenário 1 (CF antigo) } & \multicolumn{3}{c}{ Cenário 2 (Novo CF) } \\
\cline { 2 - 7 } & Total & APP & RL & Total & APP & RL \\
\hline Consumo das Famílias & $-1,04$ & $-0,70$ & $-0,33$ & $-0,54$ & $-0,37$ & $-0,17$ \\
Investimentos & $-0,56$ & $-0,33$ & $-0,23$ & $-0,28$ & $-0,16$ & $-0,12$ \\
Exportações (volume) & 3,05 & 2,22 & 0,83 & 1,59 & 1,16 & 0,42 \\
PIB real & $-0,37$ & $-0,22$ & $-0,15$ & $-0,19$ & $-0,11$ & $-0,08$ \\
Emprego & 0,00 & 0,00 & 0,00 & 0,00 & 0,00 & 0,00 \\
Salário Real & $-1,01$ & $-0,65$ & $-0,35$ & $-0,52$ & $-0,34$ & $-0,18$ \\
Estoque de Capital & $-0,60$ & $-0,36$ & $-0,25$ & $-0,30$ & $-0,18$ & $-0,13$ \\
\hline
\end{tabular}

Fonte: Dados da pesquisa. Elaboração dos autores.

Tabela 4. Impactos (variação \%) do antigo e do novo Código Florestal nas exportações setoriais, Brasil

\begin{tabular}{l|ccc|ccc}
\hline \multirow{2}{*}{ Setores } & \multicolumn{3}{c|}{ Cenário 1 (CF antigo) } & \multicolumn{3}{c}{ Cenário 2 (Novo CF) } \\
\cline { 2 - 7 } & Total & APP & $R L$ & Total & APP \\
\hline Agricultura & $-4,62$ & $-4,74$ & 0,12 & $-2,9$ & $-3,05$ & 0,15 \\
Pecuária & $-16,07$ & $-4,01$ & $-12,07$ & $-7,97$ & $-1,57$ & $-6,40$ \\
Extrativa Mineral & 1,81 & 1,29 & 0,52 & 0,97 & 0,70 & 0,27 \\
Agroindústria & $-2,45$ & $-0,83$ & $-1,62$ & $-1,27$ & $-0,34$ & $-0,93$ \\
Indústria & 5,42 & 3,84 & 1,58 & 2,89 & 2,07 & 0,83 \\
Comércio & 4,15 & 3,02 & 1,14 & 2,23 & 1,63 & 0,60 \\
Transporte & 4,10 & 2,85 & 1,24 & 2,20 & 1,54 & 0,66 \\
Serviços & 3,94 & 2,82 & 1,11 & 2,12 & 1,53 & 0,59 \\
\hline
\end{tabular}

Fonte: Dados da pesquisa. Elaboração dos autores.

e da RL, verifica-se que a maior parcela dos desdobramentos econômicos é de responsabilidade da APP, em ambos os cenários.

Observa-se ainda que os resultados obtidos para o PIB estão associados ao desempenho de importantes agregados econômicos que o compõe, como o consumo das famílias e os investimentos, que em ambos os cenários registraram retração. Para o Cenário 1, o consumo das famílias apresentou declínio de $1,04 \%$, enquanto que os investimentos se retraíram em $0,56 \%$. Já para o Cenário 2, essas variáveis apresentaram queda de $0,54 \%$ e $0,28 \%$, respectivamente. O consumo tem seu desempenho condicionado pela variação da renda, que por sua vez apresentou declínio, causado pela redução na atividade da agropecuária e consequente redução do salário real. Já a queda no nível de investimentos, dado que a taxa de retorno ao capital é exógena, é determinada pela redução da produção em praticamente todos os setores (ver Tabela 5).

As exportações, por outro lado, apresentaram comportamento diferenciado e registraram elevação em ambos os cenários, sendo que no primeiro o aumento foi de 3,05\% e no segundo de $1,59 \%$. Tal crescimento está relacionado a dois fatores, principalmente. $\mathrm{O}$ primeiro diz respeito à economia doméstica, uma vez que com a retração do PIB, do consumo, dos investimentos e dos salários há uma queda da demanda interna, tornando o mercado externo relativamente mais atraente para as vendas. Além disso, o ajuste da economia aos choques implicou elevação da taxa de câmbio em 0,65\% para o Cenário 1 e 0,35\% para o Cenário 2. Ou seja, em ambos os casos ocorreu desvalorização da moeda local, barate- 
Tabela 5. Impactos (variação \%) do antigo e do novo Código Florestal na produção setorial, Brasil

\begin{tabular}{l|ccc|ccc}
\hline \multirow{2}{*}{ Setores } & \multicolumn{3}{c|}{ Cenário 1 (CF antigo) } & \multicolumn{3}{c}{ Cenário 2 (Novo CF) } \\
\cline { 2 - 7 } & Total & APP & $R L$ & Total & APP & $-0,09$ \\
\hline Agricultura & $-1,22$ & $-1,06$ & $-0,16$ & $-0,78$ & $-0,69$ & $-0,36$ \\
Pecuária & $-1,37$ & $-0,67$ & $-0,69$ & $-0,68$ & $-0,32$ & 0,10 \\
Extrativa Mineral & 0,74 & 0,55 & 0,19 & 0,39 & 0,30 & $-0,30$ \\
Agroindústria & $-1,10$ & $-0,56$ & $-0,54$ & $-0,57$ & $-0,27$ & 0,02 \\
Indústria & 0,27 & 0,23 & 0,04 & 0,15 & 0,13 & $-0,04$ \\
Comércio & $-0,14$ & $-0,05$ & $-0,09$ & $-0,07$ & $-0,02$ & $-0,04$ \\
Transporte & $-0,21$ & $-0,10$ & $-0,11$ & $-0,09$ & $-0,04$ & $-0,12$ \\
Serviços & $-0,67$ & $-0,44$ & $-0,23$ & $-0,34$ & $-0,23$ & \\
\hline
\end{tabular}

Fonte: Dados da pesquisa. Elaboração dos autores.

ando os produtos nacionais no mercado externo, o que aumentou as exportações ${ }^{8}$.

Em termos das exportações setoriais, contudo, os resultados são distintos. Os setores que mais elevaram as suas exportações foram os da Indústria ${ }^{9}$ e Serviços, enquanto aqueles relacionados diretamente à atividade agropecuária (Agricultura, Pecuária e Agroindústria) foram os que registraram queda nas suas exportações, tanto no Cenário 1 quanto no Cenário 2. Isso se associa ao fato dos segmentos agropecuários serem os que registraram as maiores quedas de produção e também as maiores elevação dos preços, o que diminui as vantagens relativas das exportações nesses setores.

No que concerne à produção, à exceção do setor Extrativo Mineral e da Indústria, todos os demais registraram declínio, nos dois cenários. As maiores variações foram as dos setores agropecuários, alvos dos choques na redução do seu

8. Dada a importância das exportações para os resultados, realizou-se uma análise de sensibilidade com os valores das elasticidades de exportação, refazendo a solução do modelo com valores $50 \%$ inferiores e superiores aos utilizados no trabalho. Os resultados mostraram estabilidade da variável em relação a este parâmetro, não comprometendo as conclusões gerais do trabalho.

9. Notar que embora os resultados das simulações mostrem elevações nas exportações do setor Comércio e Transportes, o valor destas exportações é baixo no ano base, com Comércio representando 0,5\% das exportações totais em valor e Transportes representando $2 \%$. As exportações do setor Indústria, por outro lado, respondiam por $55 \%$ do valor exportado no ano base, enquanto as do setor Serviços por $9 \%$ daquele total. fator de produção. Dentre estes, os que tiveram a sua produção mais afetada foram o de Trigo e outros cereais ("TrigOutCere"), com declínio de 4,0\% no Cenário 1 e de 2,75\% no Cenário 2; e o de Café ("CafeGrao"), que registrou queda de 5,38\% e 3,69\%, respectivamente. Para ambos, o mecanismo da APP foi o maior responsável pela queda na produção.

Em termos agregados, verificou-se que a Agricultura, a Pecuária e a Agroindústria foram os setores que registraram declínios superiores a $1 \%$ em suas produções na simulação do antigo Código Florestal. Porém, para o Cenário 2 estas retrações foram menores, de maneira que a maior queda de produção foi de $0,78 \%$ referente à Agricultura, conforme indicado na Tabela 5 . Novamente, chama-se a atenção para o fato de que não há uma relação linear entre a redução da área colhida (ou de pastagem) e a queda na produção setorial. Esse fenômeno é decorrente das funções com rendimentos marginais decrescentes sob as quais o modelo é estruturado, bem como das possibilidades de substituição dos fatores de produção, conforme discutido anteriormente.

A redução da produção, por sua vez, levou ao aumento dos preços em alguns setores. Os segmentos cuja queda da produção foi maior (agricultura, pecuária e agroindústria) foram também aqueles em que os preços mais se elevaram: na agricultura $1,93 \%$ no cenário 1 e 1,16\% no cenário 2 , e na pecuária $6,3 \%$ e $2,08 \%$, respectivamente. Todavia, constata-se que houve setores que regis- 
Tabela 6. Impactos econômicos (variação \%) do Código Florestal sobre variáveis selecionadas no Cenário 1 e 2, por região geográfica

\begin{tabular}{lcccccc}
\hline \multicolumn{1}{c}{ Variáveis } & $\begin{array}{c}\text { N } \\
\text { (Norte) }\end{array}$ & $\begin{array}{c}\text { NE } \\
\text { (Nordeste) }\end{array}$ & $\begin{array}{c}\text { SP } \\
\text { (São Paulo) }\end{array}$ & $\begin{array}{c}\text { SER } \\
\text { (Restante do SE) }\end{array}$ & $\begin{array}{c}\text { S } \\
\text { (Sul) }\end{array}$ & $\begin{array}{c}\text { CO } \\
\text { (Centro-Oeste) }\end{array}$ \\
\hline Consumo das Famílias & \multicolumn{7}{c}{ Cenário 1 (CF antigo) } & & $-1,09$ & $-1,15$ & $-0,27$ \\
Investimentos & $-1,19$ & $-1,55$ & $-0,80$ & $-1,09$ & $-0,35$ \\
Exportações (volume) & $-0,92$ & $-0,96$ & $-0,39$ & $-0,52$ & $-0,68$ & 2,25 \\
PIB real & 3,78 & 3,68 & 3,44 & 3,57 & 1,54 & $-0,16$ \\
Emprego & $-0,88$ & $-0,76$ & $-0,14$ & $-0,38$ & $-0,51$ & $-0,37$ \\
Salário Real & $-0,20$ & $-0,29$ & 0,11 & $-0,05$ & $-0,07$ & $-1,07$ \\
Estoque de Capital & $-1,17$ & $-1,25$ & $-0,92$ & $-1,05$ & $-0,67$ & $-0,39$ \\
\hline & $-0,87$ & $-1,02$ & $-0,45$ & $-0,56$ & $-0,72$ & \\
\hline Consumo das Famílias & $-0,36$ & $-0,67$ & $-0,44$ & $-0,61$ & $-0,69$ & $-0,14$ \\
Investimentos & $-0,16$ & $-0,39$ & $-0,21$ & $-0,29$ & $-0,41$ & $-0,16$ \\
Exportações (volume) & 2,11 & 1,86 & 1,80 & 1,88 & 0,75 & 1,23 \\
PIB real & $-0,16$ & $-0,03$ & $-0,09$ & $-0,22$ & $-0,33$ & $-0,06$ \\
Emprego & 0,09 & $-0,09$ & 0,05 & $-0,05$ & $-0,09$ & 0,20 \\
Salário Real & $-0,43$ & $-0,58$ & $-0,49$ & $-0,57$ & $-0,60$ & $-0,34$ \\
Estoque de Capital & $-0,16$ & $-0,42$ & $-0,24$ & $-0,31$ & $-0,43$ & $-0,18$ \\
\hline
\end{tabular}

Fonte: Dados da pesquisa. Elaboração dos autores.

traram queda nos preços mesmo tendo sua produção retraída, como o Comércio e Transporte, que são setores de margens, bem como Serviços, cuja produção vincula-se, em geral, ao nível de atividade da economia.

Regionalmente, os impactos econômicos apresentaram-se distintos entre as versões do Código. Enquanto que no $\mathrm{CF}$ antigo as áreas que tiveram o seu PIB mais afetado foram as regióes Norte $(-0,88 \%)$ e Nordeste $(-0,76 \%)$, na nova legislação as maiores retrações foram registradas pelo Sul $(-0,33 \%)$ e pelo restante do Sudeste $(-0,22 \%)$, que não inclui o estado de São Paulo, conforme dados apresentados na Tabela 6. Regiões economicamente importantes, como o estado de São Paulo e a região Centro-Oeste, foram pouco impactadas pelas restrições de ambas as versões do $\mathrm{CF}$, o que colaborou para que a economia nacional não obtivesse maiores retrações. Neste particular, observa-se que mesmo com queda na produção agrícola e pecuária, o estado de São Paulo não registrou perdas elevadas no PIB, dada a participação relativamente pequena desses setores no PIB do estado ${ }^{10}$.

10. Para o estado de São Paulo, a Agricultura representa 1,6\% do Valor Adicionado Bruto, enquanto que no Brasil esse
Já na região Centro-Oeste, os estados de Goiás e Mato Grosso do Sul registraram crescimento no PIB, diminuindo, portanto, as perdas regionais agregadas.

Os resultados mostram que as regiões economicamente mais beneficiadas pelas modificações na legislação seriam a Norte e a Nordeste, uma vez que as perdas seriam menores no segundo cenário. Isso se deve ao fato de que a agropecuária, atividade favorecida pelas restrições mais brandas para RL e APP no Cenário 2, tem uma participação relativamente elevada na base econômica dessas regiões. Por outro lado, o Sul e o restante do Sudeste não tiveram suas atividades agropecuárias beneficiadas na mesma magnitude e, portanto, os impactos sobre o PIB não foram tão discrepantes entre os cenários.

Em relação às demais variáveis, verificou-se que o consumo das famílias, o estoque de capital e os investimentos retraíram-se em todas as regiões e em ambos os cenários, ao passo que as exportações se elevaram. O emprego e os salários foram as exceções, registrando dinâmicas

percentual é de 5,6 e, nos estados de Goiás e Paraná, é de 14 e 7,7 , respectivamente. 
distintas. Enquanto que para a economia nacional não ocorre alteração na mão-de-obra, por causa da pressuposição de pleno emprego adotada no fechamento do modelo, ao nível regional há mudanças nessa variável. Observa-se, por exemplo, que no Cenário 1 (antigo $\mathrm{CF}$ ), as regiões Norte e Nordeste são as que apresentam as maiores quedas no nível de emprego, com variações de $-0,20 \%$ e $-0,29 \%$, respectivamente. Essa mão-de-obra, por sua vez, seria absorvida pelo estado de São Paulo $(0,11 \%)$ e pela região Centro-Oeste $(0,37 \%)$. No Cenário 2 , a exceção da região Norte que passa a apresentar leve aumento no nível de emprego, o comportamento é similar, mas com menores variações.

A dinâmica de alocação do trabalho entre as regiões está relacionada ao nível de atividade econômica e ao salário real. Verifica-se, por exemplo, que as áreas que absorveram mão de obra, como o estado de São Paulo e a região Centro-Oeste, foram aquelas em que ocorreram as menores perdas no nível salarial, fazendo com que os salários reais se elevassem nessas regiões em relação às demais, o que está associado às retrações relativa- mente pequenas no PIB nesses estados. De outro modo, as regiões Norte e Nordeste, além das maiores perdas no Produto também registraram as maiores quedas no salário, impulsionando, portanto, a emigração do trabalho.

No que diz respeito à produção, os impactos são bem distintos entre as regiões e entre os cenários. Os setores mais afetados seriam, em geral, aqueles relacionados com as restrições no uso do fator terra - como as atividades da agropecuária e a agroindústria. Outros setores, como o Comércio e, principalmente, os Serviços, também sofreram impactos relevantes, todavia com as variações sendo, na maioria dos casos, relativamente menores, como pode ser verificado nos dados da Tabela 7.

Em termos geográficos, verifica-se que no primeiro cenário os impactos setoriais são maiores nas regiões Norte, Nordeste e no restante do Sudeste, enquanto que no segundo cenário as áreas mais afetadas são o restante do Sudeste e a região Sul. A dinâmica apresentada é similar ao comportamento do PIB das regiões para as diferentes versões do Código, em que se observou que as áreas

Tabela 7. Impactos econômicos (variação \%) do Código Florestal sobre a produção setorial nos cenários 1 e 2 , por região geográfica

\begin{tabular}{|c|c|c|c|c|c|c|}
\hline Variáveis & $\begin{array}{c}\mathrm{N} \\
\text { (Norte) }\end{array}$ & $\begin{array}{c}\mathrm{NE} \\
\text { (Nordeste) }\end{array}$ & $\begin{array}{c}\text { SP } \\
\text { (São Paulo) }\end{array}$ & $\begin{array}{c}\text { SER } \\
\text { (Restante do SE) }\end{array}$ & $\begin{array}{c}\text { S } \\
\text { (Sul) }\end{array}$ & $\begin{array}{c}\mathrm{CO} \\
\text { (Centro-Oeste) }\end{array}$ \\
\hline \multicolumn{7}{|c|}{ Cenário 1 (CF antigo) } \\
\hline Agricultura & $-2,22$ & $-0,54$ & $-0,34$ & $-3,05$ & $-1,65$ & $-0,10$ \\
\hline Pecuária & $-4,52$ & $-1,09$ & $-1,99$ & $-1,10$ & $-1,57$ & 0,93 \\
\hline Extrativa Mineral & 0,59 & 0,73 & 0,89 & 0,75 & 1,06 & 0,65 \\
\hline AgroIndústria & $-5,05$ & $-1,06$ & $-0,75$ & $-0,87$ & $-1,73$ & 0,07 \\
\hline Indústria & $-0,21$ & 0,02 & 0,47 & 0,25 & 0,27 & $-0,24$ \\
\hline Comércio & $-0,35$ & $-0,56$ & 0,17 & $-0,13$ & $-0,38$ & $-0,10$ \\
\hline Transporte & $-0,74$ & $-0,75$ & $-0,01$ & $-0,14$ & $-0,25$ & $-0,13$ \\
\hline Serviços & $-0,99$ & $-1,18$ & $-0,50$ & $-0,72$ & $-0,70$ & $-0,34$ \\
\hline \multicolumn{7}{|c|}{ Cenário 2 (Novo CF) } \\
\hline Agricultura & $-0,63$ & $-0,32$ & $-0,28$ & $-2,01$ & $-1,14$ & $-0,10$ \\
\hline Pecuária & $-1,59$ & $-0,29$ & $-1,96$ & $-0,60$ & $-1,09$ & 0,64 \\
\hline Extrativa Mineral & 0,32 & 0,37 & 0,48 & 0,40 & 0,59 & 0,36 \\
\hline AgroIndústria & $-1,01$ & $-0,27$ & $-0,42$ & $-0,54$ & $-1,07$ & 0,11 \\
\hline Indústria & 0,07 & 0,03 & 0,25 & 0,13 & 0,14 & $-0,12$ \\
\hline Comércio & 0,10 & $-0,20$ & 0,08 & $-0,10$ & $-0,27$ & $-0,02$ \\
\hline Transporte & $-0,08$ & $-0,28$ & 0,00 & $-0,08$ & $-0,15$ & $-0,04$ \\
\hline Serviços & $-0,27$ & $-0,50$ & $-0,27$ & $-0,40$ & $-0,42$ & $-0,16$ \\
\hline
\end{tabular}

Fonte: Dados da pesquisa. Elaboração dos autores. 
mais beneficiadas pelas mudanças na legislação foram as regiões Norte e Nordeste. Setorialmente, a produção da agropecuária e da agroindústria dessas regiões, sobretudo a da região Norte, é mais restringida pelos mecanismos do CF antigo. Já no segundo cenário, em que algumas isenções e compensações são concedidas (ver Quadro 3), a produção daqueles segmentos não sofre variações tão elevadas. Para as regiões que não são tão afetadas pelas menores restrições do novo $\mathrm{CF}$, a exemplo da Sul e do estado de São Paulo, os impactos setoriais entre os cenários são menos discrepantes, conforme exposto na Tabela 7 .

\section{Impactos econômicos: cenário 3}

Conforme mencionado anteriormente, o Cenário 3 é tratado de forma isolada nesta seção devido às suas peculiaridades, conforme descrito a seguir. Com base no novo Código Florestal, este cenário considera a compensação do déficit de RL, ou parte dele, em outra UF, desde que no mesmo bioma de origem. Esse mecanismo de compensação, que o diferencia do Cenário 2, é um dos novos componentes da Lei n. 12.651/2012 e possibilita que os produtores de áreas mais produtivas e com preço da terra mais elevado, a exemplo do estado de São Paulo, não tenham a obrigatoriedade de reverter parte de sua propriedade em vegetação natural, uma vez que a área de preservação pode estar situada em outra localidade $^{11}$. Nesse sentido, o objetivo do Cenário 3 é justamente modelar um sistema de compensação para as Reservas Legais e verificar quais os seus impactos no sistema econômico e nas regiões.

A estratégia adotada para esta simulação restringe-se a dois biomas - o cerrado e a mata atlântica - nos quais se situa a maior parte da produção agropecuária do país e, por conseguinte, é onde estão localizados os maiores empecilhos para a reversão de áreas produtivas em vegeta-

11. A legislação determina que cabem às UFs determinar qual parte do seu território poderá ser destinado a este tipo de compensação e as formas pelas quais os produtores poderão usufruir deste mecanismo. ção nativa. Para os demais biomas admite-se que a compensação de RL é feita da mesma forma que no Cenário 2, ou seja, dentro do próprio imóvel rural e, por conseguinte, na mesma UF.

No caso do bioma Cerrado, verifica-se pelos dados da Tabela 8 que apenas o estado de São Paulo possui déficit de Reserva Legal. Por outro lado, uma série de UFs possui excedente de vegetação natural nesse bioma, de maneira que parte dessa área pode ser utilizada para a compensação do déficit paulista.

Dessa forma, adotou-se o critério de que o déficit de RL do estado de São Paulo (0,67 Mha) seria compensado nos estados do Maranhão e do Piauí, com cada um recebendo 50\% do déficit paulista. A opção por esses estados como é norteada pelo fato de que, nessas regiões, a produtividade agrícola é relativamente baixa ${ }^{12}$, o que, a priori, induziria os produtores paulistas às tais áreas devido aos maiores ganhos comparativos e preços de terra mais baixos. Assim, após a implantação desse modelo o estado de São Paulo não registraria mais déficit no Cerrado e os estados do Maranhão e do Piauí teriam seu saldo de vegetação natural disponível diminuído em aproximadamente 0,34 Mha cada.

Ressalta-se que os efeitos econômicos da modelagem ocorrem somente no estado de São Paulo, pois áreas produtivas nesse estado não precisarão mais ser revertidas em vegetação natural para atender as exigências de RL, de forma que os impactos das restrições do CF são mitigados. Por outro lado, nas UFs receptoras registra-se diminuição do saldo disponível de vegetação natural, não sendo afetadas as atividades produtivas ${ }^{13}$.

Para a Mata Atlântica, diferentemente do Cerrado, vários estados registram déficit de Reserva Legal e poucos apresentam área de vegetação natural superior à exigida, como pode ser

12. De acordo com os dados do Censo Agropecuário de 2006, o valor de produção (em mil reais) por hectare colhido é de 0,80 no Piauí e de 1,29 no Maranhão, enquanto que a média brasileira é de 1,83 e a do estado de São Paulo é 3,64.

13. Nota-se que este tipo de compensação reduziria o saldo disponível nas regiões receptoras, ou seja, o montante do estoque da vegetação natural que poderia vir a ser utilizado no futuro. 
Tabela 8. Vegetação Natural (VN) fora da área de proteção, exigência e déficit de RL e Saldo de Vegetação natural (em Mha) do novo Código Florestal no bioma Cerrado, por estados selecionados

\begin{tabular}{|c|c|c|c|c|}
\hline UF & $\begin{array}{l}\text { Vegetação Natural fora de } \\
\text { Área de Proteção }\end{array}$ & $\begin{array}{c}\text { Exigência de } \\
\text { RL }\end{array}$ & $\begin{array}{l}\text { Déficit de } \\
\text { RL }\end{array}$ & $\begin{array}{c}\text { Saldo de Vegetação } \\
\text { Natural }\end{array}$ \\
\hline Bahia & 8,59 & 1,85 & 0,00 & 6,74 \\
\hline Distrito Federal & 0,13 & 0,08 & 0,00 & 0,05 \\
\hline Goiás & 10,05 & 5,84 & 0,00 & 4,21 \\
\hline Maranhão & 10,86 & 4,21 & 0,00 & 6,65 \\
\hline Minas Gerais & 11,83 & 5,18 & 0,00 & 6,64 \\
\hline Mato Grosso & 4,88 & 4,05 & 0,00 & 0,83 \\
\hline Mato Grosso do Sul & 12,87 & 9,84 & 0,00 & 3,03 \\
\hline Pará & 0,00 & 0,00 & 0,00 & 0,00 \\
\hline Paraná & 0,08 & 0,07 & 0,00 & 0,02 \\
\hline Piauí & 5,17 & 1,00 & 0,00 & 4,17 \\
\hline Rondônia & 0,01 & 0,00 & 0,00 & 0,00 \\
\hline São Paulo & 0,75 & 1,42 & 0,67 & 0,00 \\
\hline Tocantins & 13,25 & 6,97 & 0,00 & 6,28 \\
\hline
\end{tabular}

Fonte: AgLue; Dados da pesquisa. Elaboração dos autores.

observado na Tabela 9. Vale ainda destacar que para a Mata Atlântica, o Decreto 6.660/2008 institui determinações específicas de forma que o excedente entre a área de vegetação natural e o exigido para a RL não constitui saldo, ou seja, essa área não pode ser suprimida para dar origem à atividade produtiva. No entanto, pode ser considerada no cenário de compensação, uma vez que esse processo exige a preservação da área e não sua supressão.

A modelagem nesse caso considerou, além da área disponível nos estados, as variações no

Tabela 9. Exigências territoriais (em Mha) e variação no preço da terra no bioma Mata Atlântica (Cenário 2) a para adequação ao novo Código Florestal, por unidade da federação

\begin{tabular}{|c|c|c|c|c|c|c|c|}
\hline UF & $\begin{array}{l}\text { Veg Natural fora de } \\
\text { Área de Proteção }\end{array}$ & $\begin{array}{c}\text { Exigência de } \\
\text { RL }\end{array}$ & $\begin{array}{l}\text { Déficit de } \\
\text { RL }\end{array}$ & $\begin{array}{l}\text { Saldo de } \\
\text { VN }\end{array}$ & $\begin{array}{c}\text { Elevação de preço } \\
\text { decorrente da APP } \\
(\%) \text { no Cenário } 2\end{array}$ & $\begin{array}{l}\text { Área } \\
\text { disp. }\end{array}$ & $\begin{array}{l}\text { Aptidão para } \\
\text { compensação }\end{array}$ \\
\hline $\mathrm{AL}$ & 0,05 & 0,16 & 0,11 & 0,00 & 73,27 & $-0,11$ & \\
\hline BA & 2,24 & 1,47 & 0,00 & 0,00 & 13,83 & 0,77 & Apto \\
\hline ES & 0,49 & 0,62 & 0,13 & 0,00 & 13,26 & $-0,13$ & \\
\hline GO & 0,18 & 0,17 & 0,00 & 0,00 & 21,98 & 0,02 & Apto \\
\hline MG & 4,39 & 3,53 & 0,00 & 0,00 & 13,59 & 0,86 & Apto \\
\hline MS & 0,84 & 0,89 & 0,05 & 0,00 & 16,57 & $-0,05$ & \\
\hline $\mathrm{PB}$ & 0,03 & 0,06 & 0,03 & 0,00 & 28,71 & $-0,03$ & \\
\hline $\mathrm{PE}$ & 0,07 & 0,19 & 0,12 & 0,00 & 105,91 & $-0,12$ & \\
\hline PR & 3,09 & 3,34 & 0,25 & 0,00 & 47,69 & $-0,25$ & \\
\hline RJ & 0,51 & 0,56 & 0,05 & 0,00 & 1,73 & $-0,05$ & \\
\hline $\mathrm{RN}$ & 0,05 & 0,04 & 0,00 & 0,00 & 3,50 & 0,01 & Apto \\
\hline RS & 1,85 & 1,79 & 0,00 & 0,00 & 85,60 & 0,06 & Não apto \\
\hline SC & 2,21 & 1,53 & 0,00 & 0,00 & 64,47 & 0,68 & Não apto \\
\hline $\mathrm{SE}$ & 0,07 & 0,11 & 0,04 & 0,00 & 2,21 & $-0,04$ & \\
\hline SP & 1,95 & 2,72 & 0,77 & 0,00 & 16,28 & $-0,77$ & \\
\hline
\end{tabular}

Fonte: AgLue; dados da pesquisa. Elaboração dos autores. 
preço da terra decorrentes do cumprimento das exigências da Área de Preservação Permanente no Cenário 2. A inclusão dessa variável foi pelo fato de na Mata Atlântica ser forte a presença de culturas em áreas acidentadas e que estão no raio de abrangência das delimitações da APP, como topo de morro e várzeas. Assim, as oscilações no preço da terra decorrentes do atendimento a este instrumento, e observadas no Cenário 2, seriam altas o suficiente para influenciar na alocação da compensação da Reserva Legal. Observa-se na Tabela 9 que em algumas UFs os preços da terra elevaram-se sensivelmente o que dificultaria a utilização de suas áreas como receptoras da compensação.

O critério para a escolha dos estados receptores, portanto, foi a combinação entre a disponibilidade de área e o aumento no preço da terra (observados na simulação do Cenário 2). Verificou-se a existência de terras disponíveis em seis UFs (BA, GO, MG, RN, RS e SC), porém em duas destas, RS e SC, o aumento do preço da terra decorrente das restrições da APP foi elevado, restando quatro estados passíveis de receber as compensações: Bahia (BA), Goiás (GO), Minas Gerais (MG) e Rio Grande do Norte (RN). Por outro lado, nove estados registraram déficit de RL, dentre os quais o estado de São Paulo e o Paraná, que são importantes atores na produção agropecuária brasileira.

Dentre as várias combinações possíveis entre deficitários e receptores, optou-se por compensar os déficits dos estados de São Paulo e do Paraná, que juntos totalizam 1,02 Mha, nas áreas disponíveis nos estados de Minas Gerais e da Bahia (50\% em cada UF), que possuem a maior disponibilidade territorial - 1,63 Mha conjuntamente, e que registraram a menor elevação de preços da terra no Cenário 2. Dessa forma, o estado de São Paulo passaria a não ter mais nenhum déficit de RL, pois já teria mecanismo de compensação para os déficits de ambos os biomas que o compõe (cerrado e mata atlântica), de maneira similar ao estado do Paraná, cujo único déficit, o da Mata Atlântica, estaria sendo compensado. Já a Bahia e as Minas Gerais teriam as suas áreas aptas ao mercado de compensações reduzidas em 0,51
Mha cada. Como visto anteriormente para ocaso do Cerrado, esperam-se variações nos impactos econômicos dos estados de origem da compensação, enquanto que nas UFs receptoras não há expectativa de desdobramentos nesse sentido, visto que o cenário não afeta nenhum aspecto produtivo.

Com base nesse sistema de compensação, os percentuais de redução da área colhida (ou de pastagem) passam a ser distintos dos utilizados no Cenário 2. Como pode ser observado nos dados da Tabela 10, os estados de São Paulo e do Paraná passam a ter uma menor necessidade de redução da sua área colhida ou de pastagem para atender as exigências legais. Por outro lado, nos estados receptores não há alterações, conforme já discutido.

Setorialmente os resultados são semelhantes aos do Cenário 2. As exceções, contudo, cabem aos segmentos da pecuária, que pelos critérios assumidos são os mais afetados pela RL, e ao cultivo da Cana-de-açúcar e das Frutas Cítricas, cuja necessidade de redução diminui notavelmente entre os cenários. Esse resultado, particularmente, está associado ao fato de que o plantio dessas culturas é predominante no estado de São Paulo e no Paraná, no caso da cana-de-açúcar, e foram diretamente beneficiadas pelo sistema de compensação. Na ausência do mecanismo compensatório tais culturas teriam que reduzir a sua área colhida no estado de São Paulo em 4,32\% (cana-de-açúcar) e 4,58\% (frutas cítricas), respectivamente, enquanto que com a implantação do mecanismo não seria necessária esta redução.

Os efeitos econômicos desta simulação foram similares aos observados no Cenário 2. O PIB registrou retração de $0,17 \%$, ou seja, somente 0,02 pontos percentuais (p.p.) a menos que a variação da segunda simulação. Essa diferença, vale frisar, é creditada aos efeitos do mecanismo da RL, que no Cenário 2 foram de $-0,08 \%$ e nesta simulação foram de $-0,06 \%$. As demais variáveis também apresentaram comportamento similar, sendo as diferenças entre os resultados das simulações apenas marginais e menores que 0,1 pontos percentuais (p.p.). 
Tabela 10. Cenário 3: \% de redução da área colhida (ou de pastagem) para adequação ao Novo Código Florestal com o mecanismo de compensação de RL, por UF

\begin{tabular}{|c|c|c|c|}
\hline UF & APP (\%) & RL (\%) & Total $(\%)$ \\
\hline Rondônia & 5,17 & 30,22 & 35,39 \\
\hline Acre & 5,35 & 22,11 & 27,46 \\
\hline Amazonas & 13,44 & 6,09 & 19,53 \\
\hline Roraima & 5,64 & 1,70 & 7,34 \\
\hline Pará & 9,99 & 27,05 & 37,04 \\
\hline Amapá & 15,46 & 4,33 & 19,80 \\
\hline Tocantins & 7,63 & 13,47 & 21,10 \\
\hline Maranhão & 13,92 & 19,35 & 33,27 \\
\hline Piauí & 9,29 & 0,93 & 10,22 \\
\hline Ceará & 9,65 & 1,31 & 10,97 \\
\hline Rio Grande do Norte & 17,62 & 2,97 & 20,58 \\
\hline Paraíba & 12,25 & 2,14 & 14,38 \\
\hline Pernambuco & 19,04 & 2,95 & 21,98 \\
\hline Alagoas & 17,89 & 4,05 & 21,94 \\
\hline Sergipe & 12,40 & 4,56 & 16,95 \\
\hline Bahia & 14,19 & 6,54 & 20,73 \\
\hline Minas Gerais & 17,14 & 6,04 & 23,18 \\
\hline Espírito Santo & 28,76 & 32,87 & 61,63 \\
\hline Rio de Janeiro & 25,83 & 11,93 & 37,76 \\
\hline São Paulo & 8,46 & 0,00 & 8,46 \\
\hline Paraná & 14,82 & 0,00 & 14,82 \\
\hline Santa Catarina & 20,42 & 5,29 & 25,71 \\
\hline Rio Grande do Sul & 16,23 & 10,41 & 26,64 \\
\hline Mato Grosso do Sul & 5,62 & 4,22 & 9,84 \\
\hline Mato Grosso & 6,22 & 20,36 & 26,58 \\
\hline Goiás & 8,75 & 4,59 & 13,34 \\
\hline Distrito Federal & 15,35 & 7,20 & 22,55 \\
\hline
\end{tabular}

Fonte: Dados da pesquisa. Elaboração dos autores.

Tabela 11. Porcentagem de redução da área colhida (ou de pastagem) para adequação ao Novo Código Florestal no Brasil com e sem o mecanismo de compensação de RL, por setores agropecuários

\begin{tabular}{l|ccc|ccc}
\hline \multicolumn{1}{c}{ Setor Agropecuário } & \multicolumn{3}{c|}{ Cenário 2 (\%) } & \multicolumn{3}{c}{ Cenário 3 (\%) } \\
\cline { 2 - 7 } & APP & RL & Total & APP & RL & Total \\
\hline 1. ArrozCasca & 15,33 & 0,33 & 15,66 & 15,33 & 0,33 & 15,65 \\
2. MilhoGrao & 10,04 & 0,61 & 10,65 & 10,04 & 0,40 & 10,44 \\
3. TrigoOutCere & 15,56 & 2,21 & 17,78 & 15,56 & 1,85 & 17,41 \\
4. CanaDeAcucar & 13,00 & 2,34 & 15,34 & 13,00 & 0,07 & 13,07 \\
5. SojaGrao & 10,41 & 1,18 & 11,59 & 10,41 & 0,97 & 11,38 \\
6. OutPrServLav & 9,99 & 0,18 & 10,17 & 9,99 & 0,10 & 10,09 \\
7. Mandioca & 16,79 & 0,17 & 16,96 & 16,79 & 0,10 & 16,89 \\
8. FumoFolha & 20,01 & 0,71 & 20,72 & 20,01 & 0,68 & 20,69 \\
9. AlgodHerb & 5,55 & 2,50 & 8,05 & 5,55 & 2,47 & 8,02 \\
10. FrutasCitric & 8,15 & 3,58 & 11,73 & 8,15 & 0,02 & 8,16 \\
11. CafeGrao & 19,92 & 0,69 & 20,61 & 19,92 & 0,61 & 20,53 \\
12. ExplFlorSilv & 16,13 & 0,17 & 16,30 & 16,13 & 0,12 & 16,26 \\
13. BovOutrAnim & 10,46 & 15,44 & 25,90 & 10,46 & 13,10 & 23,56 \\
14. LeitVacOuAni & 15,13 & 14,05 & 29,18 & 15,13 & 12,11 & 27,24 \\
15. OutPecAcq &.. &.. &.. &.. &.. \\
\hline
\end{tabular}

Fonte: Dados da pesquisa. Elaboração dos autores. 
Tabela 12. Impactos econômicos (variação \%) do novo Código Florestal com o mecanismo de compensação de RL sobre variáveis selecionadas, Brasil

\begin{tabular}{lccc}
\hline \multicolumn{1}{c}{ Variáveis } & Total $\mathbf{( \% )}$ & APP $\mathbf{( \% )}$ & RL (\%) \\
\hline Consumo das Famílias & $-0,50$ & $-0,36$ & $-0,13$ \\
Investimentos & $-0,25$ & $-0,16$ & $-0,09$ \\
Exportações (volume) & 1,50 & 1,16 & 0,35 \\
PIB real & $-0,17$ & $-0,11$ & $-0,06$ \\
Emprego & 0,00 & 0,00 & 0,00 \\
Salário Real & $-0,47$ & $-0,34$ & $-0,13$ \\
Estoque de Capital & $-0,27$ & $-0,18$ & $-0,09$ \\
\hline
\end{tabular}

Fonte: Dados da pesquisa. Elaboração dos autores.

Ao nível setorial verificou-se a mesma tendência do Cenário 2, com variações mais suaves na produção, nas exportações e nos preços. Os setores que registraram as diferenças mais expressivas entre os cenários, e, portanto, foram os mais beneficiados pelo mecanismo de compensação, foram a pecuária, cuja produção caiu 0,57\% (0,11 p.p. a menos que o Cenário 2), e a agroindústria, com $0,45 \%$ de queda na produção $(0,12$ p.p. inferior ao segundo cenário).

A pecuária foi afetada devido aos pressupostos da simulação, em que os déficits de RL foram primeiro compensados nas áreas de pastagens para que em seguida, caso aquelas fossem insuficientes, as áreas agrícolas passassem a ser utilizadas. Logo, a não supressão de áreas para atender à RL nos estados de São Paulo e do Paraná beneficiou diretamente a pecuária. Já a agroindústria, além da manutenção na produção da pecuária paulista e paranaense, teve seu desempenho também influenciado pela não redução da área colhida da Cana-de-açúcar e das Frutas Cítricas no estado de São Paulo. Ambos os cultivos possuem importantes encadeamentos produtivos, de forma que a sua manutenção ajudou a agroindústria nacional a registrar declínio de $0,45 \%$, ao invés dos 0,57\% observados no Cenário 2.

Para os demais setores as variações na produção não divergiram muito das observadas na segunda simulação. Pela Tabela 13 pode-se observar que o comportamento das exportações foi similar ao da produção, com a pecuária e a agroindústria tendo as maiores oscilações entre o segundo e o terceiro cenário e as demais variáveis impactos discretamente inferiores.

Se por um lado os impactos ao nível nacional não foram tão significativos, sobretudo na variação do PIB, por outro o sistema de compensação teve desdobramentos importantes regionalmente. O estado de São Paulo, por exemplo, registrou no

Tabela 13. Impactos econômicos (variação \%) do novo Código Florestal com o mecanismo de compensação de RL na produção e exportações setoriais, Brasil

\begin{tabular}{|c|c|c|c|c|c|c|}
\hline \multirow{2}{*}{ Setores } & \multicolumn{3}{|c|}{ Produção (\%) } & \multicolumn{3}{|c|}{ Exportações (\%) } \\
\hline & Total & $A P P$ & $R L$ & Total & $A P P$ & $R L$ \\
\hline Agricultura & $-0,73$ & $-0,69$ & $-0,04$ & $-2,85$ & $-3,06$ & 0,20 \\
\hline Pecuária & $-0,57$ & $-0,31$ & $-0,26$ & $-6,90$ & $-1,49$ & $-5,41$ \\
\hline Extrativa Mineral & 0,37 & 0,30 & 0,08 & 0,91 & 0,69 & 0,22 \\
\hline AgroIndústria & $-0,45$ & $-0,26$ & $-0,19$ & $-0,82$ & $-0,30$ & $-0,53$ \\
\hline Indústria & 0,15 & 0,13 & 0,02 & 2,66 & 2,04 & 0,62 \\
\hline Comércio & $-0,05$ & $-0,02$ & $-0,03$ & 2,06 & 1,61 & 0,45 \\
\hline Transporte & $-0,08$ & $-0,04$ & $-0,04$ & 2,00 & 1,52 & 0,48 \\
\hline Serviços & $-0,31$ & $-0,22$ & $-0,09$ & 1,95 & 1,51 & 0,44 \\
\hline
\end{tabular}

Fonte: Dados da pesquisa. Elaboração dos autores. 
Cenário 3 declínio de apenas 0,02\% no seu PIB, percentual inferior ao do Cenário 2 , cuja retração foi de $0,09 \%$. Já na região Sul, os impactos diminuíram de 0,33\% do PIB na segunda simulação para $0,27 \%$ no Cenário 3. Ao se observar isoladamente o estado do Paraná, alvo do sistema de compensação, os impactos sobre o PIB passam de $-0,32 \%$ no Cenário 2 para $-0,13 \%$ no Cenário 3. Essas mudanças nos efeitos econômicos estão associadas ao comportamento de outras variáveis, como o emprego, o consumo das famílias e os investimentos, em que tanto o estado de São Paulo quanto a região Sul registraram oscilações relativamente menores, conforme pode ser visto na Tabela 14. E, finalmente, é válido observar que as regiões Norte, Nordeste e Centro-Oeste apresentaram quedas no PIB maiores do que aquelas do Cenário 2, especialmente por causa da menor queda no PIB paulista e sulista, ao passo que as demais variáveis também registram pequenas variações. Todavia, não se observou nenhuma mudança de tendência.

\section{Considerações finais}

Os resultados obtidos mostram, portanto, que a efetiva aplicação das restrições impostas pelo novo Código levaria a redução de aproximadamente 0,19\% do PIB brasileiro (Cenário 2) ou de 0,17\% no Cenário 3, quando o déficit de RL é compensado em outra UF. Por outro lado, nos moldes da antiga legislação (Cenário 1) esse impacto seria de $0,37 \%$. Sob a ótica setorial, observou-se que, além dos segmentos agrícolas e pecuários, os setores relacionados à cadeia do agronegócio também seriam afetados nas três simulações, com destaque para as retrações dos serviços e agroindústria. Regionalmente, as regiões Norte e Nordeste apresentariam as maiores perdas de PIB no Cenário 1 (antigo CF), mas também seriam as mais beneficiadas com as mudanças na legislação. Áreas importantes para a agropecuária, como o estado de São Paulo e a região CentroOeste, não sofreriam retrações expressivas em seu PIB, o que faria com que a economia nacional não fosse tão impactada.

Observado de uma forma mais ampla, os resultados do modelo mostram que, apesar de significativos em algumas regiões, a aplicação da versão atual do Código Florestal Brasileiro não causaria impacto negativo significativo na economia nacional. Para efeito de ilustração, a retração de $0,19 \%$ do PIB obtida no Cenário 2 (novo CF) corresponde a aproximadamente R $\$ 6,2$ bilhões, enquanto que a de $0,37 \%$ referente ao Cenário 1 (antigo CF) a R\$ 12,0 bilhões, ambos a valores do ano de 2009, montantes que poderiam ser interpretados como o custo social econômico da implementação do Código Florestal. Esses valores, em termos relativos, são significativamente inferiores aos de outros estudos reportados na literatura como, por exemplo, em Rigonatto (2009), que calcula prejuízos da ordem de $\mathrm{R} \$ 2,05$ bilhões, a preços de 2008, apenas referente à reconstituição da RL no estado de Goiás, e Padilha Júnior (2004),

Tabela 14. Impactos econômicos (variação \%) do novo Código Florestal com o mecanismo de compensação de RL sobre variáveis selecionadas, por região geográfica

\begin{tabular}{lcccccc}
\hline \multicolumn{1}{c}{ Variáveis } & $\begin{array}{c}\text { N } \\
\text { (Norte) }\end{array}$ & $\begin{array}{c}\text { NE } \\
\text { (Nordeste) }\end{array}$ & $\begin{array}{c}\text { SP } \\
\text { (São Paulo) }\end{array}$ & $\begin{array}{c}\text { SER } \\
\text { (Restante do SE) }\end{array}$ & $\begin{array}{c}\text { S } \\
\text { (Sul) }\end{array}$ & $\begin{array}{c}\text { CO } \\
\text { (Centro-Oeste) }\end{array}$ \\
\hline Consumo das Famílias & $-0,47$ & $-0,71$ & $-0,32$ & $-0,59$ & $-0,59$ & $-0,23$ \\
Investimentos & $-0,21$ & $-0,42$ & $-0,14$ & $-0,28$ & $-0,33$ & $-0,22$ \\
Exportações (volume) & 2,00 & 1,80 & 1,67 & 1,74 & $-0,77$ & 1,26 \\
PIB real & $-0,22$ & $-0,33$ & $-0,02$ & $-0,23$ & $-0,27$ & $-0,13$ \\
Emprego & 0,02 & $-0,12$ & 0,08 & $-0,07$ & $-0,06$ & 0,13 \\
Salário Real & $-0,45$ & $-0,58$ & $-0,40$ & $-0,54$ & $-0,52$ & $-0,36$ \\
Estoque de Capital & $-0,21$ & $-0,45$ & $-0,17$ & $-0,30$ & $-0,36$ & $-0,24$ \\
\hline
\end{tabular}

Fonte: Dados da pesquisa. Elaboração dos autores. 
que calcula que o impacto econômico total da Reserva Legal sobre a agropecuária do Paraná pode atingir valores ao redor de $\mathrm{R} \$ 90$ bilhões, a preços de 2002.

Verifica-se, desta forma, que os efeitos de equilíbrio geral da implementação do Código Florestal Brasileiro podem ser muito distintos daqueles obtidos através do cálculo dos choques diretos exclusivamente, ou seja, dos efeitos de primeira ordem. O ajustamento do sistema econômico como um todo, levando-se em conta a substituição entre os fatores de produção, rendimentos marginais decrescentes no uso dos fatores de produção, mobilidade de trabalho, livre comércio entre regiões e a influência do sistema de preços no equilíbrio econômico levam a uma nova alocação ótima de recursos induzida pelas novas restrições ambientais, com perdas econômicas agregadas substancialmente inferiores às obtidas na literatura citada. Isso acontece porque eventuais perdas que um setor e/ou região venha a sofrer podem ser compensadas ou minimizadas por ganhos em outros setores e/ou regiões, de maneira que o resultado líquido desse processo, o resultado social da política, é que deve ser considerado.

Por fim, salienta-se que os resultados obtidos neste trabalho limitam-se aos efeitos econômicos da legislação sobre o País e as regiões de uma forma geral, não sendo possível nenhuma inferência a respeito de aspectos ambientais, ecossistêmicos, etc, o que, por sua vez, deve ser incorporado em trabalhos futuros.

\section{Referências}

BACHA, C. J. C. Eficácia da política de reserva legal no Brasil. Teoria e Evidência Econômica, Passo Fundo, v. 13, n. 25, p. 9-27, 2005.

BRASIL. Lei 4.771 de 15 de setembro de 1965.

BRASIL. Lei 12.651 de 25 de maio de 2012.

DINIZ, T. B. Impactos socioeconômicos do Código Florestal Brasileiro: uma discussão à luz de um modelo computável de equilíbrio geral. 2013. Dissertação (Mestrado em Economia Aplicada) - Escola Superior de Agricultura Luiz de Queiroz, Universidade de São Paulo, Piracicaba, 2013. Disponível em: <http://www. teses.usp.br/teses/disponiveis/11/11132/tde-21022013150919/>. Acesso em: 21 fev. 2014.

DIXON, P.; PARMENTER, B.; SUTTON, J.; VICENT, D. ORANI: a multisectoral model of the Australian economy. Amsterdam: North-Holland, 1982. v. 1.

FACHINELLO, A. L. Avaliação do impacto econômico de possíveis surtos da gripe aviária no Brasil: uma análise de equilíbrio geral computável. 2008. 160 p. Tese (Doutorado em Ciências) - Escola Superior de Agricultura "Luiz de Queiroz", Universidade de São Paulo, Piracicaba, 2008.

FERREIRA FILHO, J. B. S. Introdução aos modelos de equilíbrio geral: conceitos, teoria e aplicações. 2010. 31 p. Piracicaba: Escola Superior de Agricultura "Luiz de Queiroz", 2010. Disponível em: < http://www.economia. esalq.usp.br/ jbsferre>. Acesso em: 15 dez. 2010.

. e HORRIDGE, M. J. The Doha Development Agenda and Brazil: Distributional Impacts. Review of Agricultural Economics, v. 28, p. 362, 2006a.

. e HORRIDGE, M. J. Economic Integration, Poverty and Regional Inequality in Brazil. Revista Brasileira de Economia, v. 60, p. 363-387, 2006 b.

. e HORRIDGE, J. M. Would World Agricultural Trade Liberalization Help the Poor of Brazil? In ANDERSON, K., COCKBURN, J. e MARTIN, W. (Ed.). Agricultural Price Distortions, Inequality and Poverty. Washington DC: The World Bank, 2008. chap. 13, p. 391-423.

GLOBAL TRADE ANALYSIS PROJECT - GTAP. Global trade, assistance and production: the GTAP 8 database. Purdue: Purdue University, Center for Global Trade Analysis, 2008.

HARRISON, J. e PEARSON, K. Computing solutions for Large General Equilibrium Models using Gempack. Computational Economics, Princeton, v. 9, p. 83-127, 1996.

HORRIDGE, M. The TERM model and its data base. General Paper No.G-219.Centre of Policy Studies, Monash University.July, 2011.

INSTITUTO BRASILEIRO DE GEOGRAFIA E ESTATÍSTICA - IBGE. Censo Agropecuário 2006. Rio de Janeiro, 2009. 777 p.

INSTITUTO DE PESQUISA ECONÔMICA APLICADA - IPEA. Código Florestal: Implicações do PL 1876/99 nas Áreas de Reserva Legal. Brasília, 2011. 23 p.

PADILHA JÚNIOR, J. B. O Impacto da Reserva Legal Florestal sobre a Agropecuária Paranaense, em um Ambiente de 
Risco. 2004. 181 p. Tese (Doutorado em Ciências Florestais) - Universidade Federal do Paraná, Curitiba, 2004.

RIGONATTO, C. A. O custo da sustentabilidade ambiental. In: SEMINÁRIO DE LEGISLAÇÃO AMBIENTAL - O CÓDIGO AMBIENTAL EM DEBATE, 2009, Goiânia. Seminário de Legislação Ambiental - O Código Ambiental em Debate. Goiania: Faeg, 2009. v. 1. p. 8-17.

SPAROVEK, G., BARRETO, A., KLUG, I., PAPP, L. e LINO, J. A revisão do Código Florestal brasileiro. Novos Estudos, São Paulo, n. 89, p. 181-205, 2011.
SPAROVEK, G., BERNDES, G., KLUG, I. e BARRETTO, A. Brazilian Agriculture and Environmental legislation: Status and Future Challenges. Environmental Science $\mathcal{E}$ Technology, Iowa City, v. 44, n. 16, p. 6046-6053, 2010.

TOURINHO, O. A. F., KUME, H. e PEDROSO, A.C. de S. Elasticidades de Armington para o Brasil: 19862002, novas estimativas. Rio de Janeiro: Instituto de Pesquisa Econômica Aplicada, 2003. 22 p. (Texto para Discussão, 974). 
